\title{
Meta
}

Journal des traducteurs

Translators' Journal

\section{Simon, Sherry (1994) : Le trafic des langues. Traduction et culture dans la littérature québécoise, Montréal, Boréal, 224 p.}

\section{Alexis Nouss}

Volume 41, numéro 3, septembre 1996

URI : https://id.erudit.org/iderudit/003747ar

DOI : https://doi.org/10.7202/003747ar

Aller au sommaire du numéro

Éditeur(s)

Les Presses de l'Université de Montréal

ISSN

0026-0452 (imprimé)

1492-1421 (numérique)

Découvrir la revue

Citer ce compte rendu

Nouss, A. (1996). Compte rendu de [Simon, Sherry (1994) : Le trafic des langues.

Traduction et culture dans la littérature québécoise, Montréal, Boréal, 224 p.]

Meta, 41(3), 483-485. https://doi.org/10.7202/003747ar

Ce document est protégé par la loi sur le droit d'auteur. L'utilisation des services d'Érudit (y compris la reproduction) est assujettie à sa politique d'utilisation que vous pouvez consulter en ligne.

https://apropos.erudit.org/fr/usagers/politique-dutilisation/
Cet article est diffusé et préservé par Érudit.

Érudit est un consortium interuniversitaire sans but lucratif composé de l’Université de Montréal, l'Université Laval et l'Université du Québec à Montréal. Il a pour mission la promotion et la valorisation de la recherche. https://www.erudit.org/fr/ 
SIMON, Sherry (1994) : Le trafic des langues. Traduction et culture dans la littérature québécoise, Montréal, Boréal, 224 p.

Plus encore que le titre, très beau dans sa polysémie - mouvement et impureté, circulation et transgression -, c'est le sous-titre qui, d'emblée, donne la visée et la mesure de l'ouvrage. «Traduction et culture dans la littérature québécoise», c'est presque le sous-titre du livre séminal d'Antoine Berman L'Épreuve de l'étranger. Culture et traduction dans l'Allemagne romantique, auquel Sherry Simon reconnaît sa dette (la dette du traducteur ?). À une nuance près, cependant: l'ordre des signifiants culture et traduction. Là où l'Allemagne utilisa la traduction pour façonner le matériau de sa culture (et par là même, pour inventer la culture), Sherry Simon voit dans la traduction bien plus qu'une simple composante mais véritablement un agent de formation culturelle, une matrice identitaire repérable et thématisable non seulement dans le cas du Québec mais applicable à l'échelle du monde contemporain en ce qu'elle est susceptible d'accueillir et de susciter les confrontations nécessaires aux équilibres communautaires et individuels.

L'auteur insère sa réflexion sur la traduction dans le contexte d'une recherche plus globale qu'elle mène depuis plusieurs années sur les dynamiques hétérogènes, plurilingues et multiculturelles des sociétés actuelles, sur les mouvements et franchissements des frontières culturelles, sur les échanges interlinguistiques entre les ensembles nationaux et à l'intérieur de leurs limites. Ce faisant, elle ne minorise pas la fonction de la traduction mais lui donne au contraire une place centrale dans l'épistémè qui est la nôtre: «Dans le contexte culturel actuel, la traduction apparaît comme porteuse d'une mission symbolique particulièrement chargée: elle représente les complexités de la communication dans le monde contemporain.» (p. 17) «Poétique de la traduction» qui altère le texte par la langue étrangère, revalorisation de la traduction comme activité créatrice, surgissement de nouvelles entités culturelles où la traduction agit subversivement au service d'idéologies de libération (féminisme ou post-colonialisme), écriture plurilingue comme arme de contestation, littérature québécoise des années quatre-vingt fragilisant le dogme de l'homogénéité identitaire, autant de thèmes que l'auteur interroge pour théoriser ce qu'elle appelle le phénomène de la «traduction inachevée» qui bouscule la normativité et révèle «l'identité culturelle comme un processus de négociation toujours en cours» (p. 33).

C'est cependant le corpus québécois qui est essentiellement à l'étude, abordé dans une approche socio-historique désormais bien installée dans le champ traductologique et dont Sherry Simon - qui a été traductrice de Foucault - maîtrise et pratique admirablement les paramètres critiques. Précédant les six sections consacrées aux productions littéraires marquées par le processus traductif ou l'hybridité langagière, le chapitre premier s'interroge sur le rapport idéologique entre culture et traduction au Québec, entre une valence négative si la culture est défendue comme homogène et autarcique et un affect positif si la culture participe d'une dynamique d'ouverture et de transformation. Les deux positions sont historiquement situées et Sherry Simon dégage pertinemment les «concrétions discursives» ayant établi le sous-sol idéologique de la perception de la traduction comme corruption de la langue et de la culture. Citant divers auteurs chez qui l'accusation d'asservissement puis la critique antiaméricaniste et anticolonialiste éclairent les positions contre la traduction, elle affirme: $«[. .$.$] le refus de la traduction, au nom de$ la culture authentique, repose sur l'idée de 'préserver' une culture définie comme un ensemble clos. Dès que la culture est par contre conçue comme un jeu de différences, où mémoire et nouveauté, références propres et étrangères sont en interaction constante, il devient possible de concevoir le passage linguistique et culturel comme un élément essentiel de création collective, donc de l'identité culturelle.» (p. 47) 
À cette fixation fantasmatique sur le risque de pollution et de contamination par la traduction - l'anthropologie a abondamment étudié la fonction de la souillure dans les procédures d'auto-perception -, un certain nombre d'œuvres, écrites dans les vingt dernières années, opposent la vivacité et l'audace de leur projet et révèlent combien «[qu'elle] soit portée par le refus ou par le désir de la différence, par une visée identitaire ou ethnographique, la traduction actualise les frontières linguistiques et crée le rapport à l'altérité» (p. 55). Un premier groupe d'auteurs intégrent la traduction, thème ou pratique, dans la facture de leurs écrits: Jacques Brault et sa politique traductionnelle d'appropriation et de décentrement, Nicole Brossard et la dissolution des rapports textuels d'autorité, A. M. Klein et la «traduction disjonctive» (archaïsmes et fusion des idiomes) exprimant la nature composite du présent. Le second groupe de créateurs traités relèvent d'une «esthétique de la dissonance» dans laquelle les différences langagières exercent une fonction déstabilisatrice: l'angoisse du flottement et de l'impureté identitaires chez Daniel Gagnon, la multiplicité conflictuelle des codes se croisant au sein du tissu urbain dans les romans de Francine Noël, Monique LaRue ou Régine Robin, le choc des altérités dans le théâtre de Marco Micone ou Robert Lepage. Ces six chapitres, six analyses pertinemment et finement cernées, peuvent apparaître comme une série de variations sur le thème d'une «esthétique postmoderne de la reprise et du redoublement parodique» (p. 26) où «mécanisme de recyclage des matières culturelles usées, générateur de la nouveauté à partir des sources connues, la traduction est répétition et nouveauté» (p. 76).

Même si je ne partage pas sa croyance dans l'efficacité conceptuelle de l'idée de post-modernité (lorsqu'elle oppose, autour de ce paradigme, Klein à Robin par exemple) qui n'a, à mes yeux, qu'une valeur symptomatique et qu'une potentialité formelle, voire formaliste, on ne peut que savoir gré à l'auteur de nous fournir sur le plan opératoire, au fil de ses lectures attentives, tout un lexique conceptuel d'une grande utilité à la constitution d'un vocabulaire critique en traductologie ${ }^{1}$. Je ne retiendrai, à titre d'exemple, outre les notions déjà citées, que celle de «traduction latérale» avancée à propos des versions en yiddish et en écossais des Belles-sceurs de Tremblay et aussi, pour mémoire, celle de «mixité jubilatoire» (sur Klein) ou d'«esthétique de la faiblesse» (sur D. Gagnon). Il ne s'agit pas de simple bonheur d'expression (ce qui serait déjà louable, le travail critique se prouvant de sa capacité à thématiser). Ce que nous propose ici Sherry Simon, dans le nouveau paysage herméneutique dressé à la suite de la rupture épistémologique poststructuraliste, tient à la constitution d'un espace réflexif où «l'hybridité culturelle» sera interrogée par le biais du texte littéraire travaillé par la traduction. La littérature québécoise offre à cet égard un remarquable laboratoire de pratiques (plurilinguisme et ludisme langagier) sur lequel s'appuie l'auteur afin de dégager de nouvelles définitions: «Que se passe-t-il si les langues et les cultures 'de départ' se révèlent déjà plurielles? Alors il faut reconceptualiser la traduction pour y voir une opération qui n'aboutit pas toujours à un résultat homogène mais qui - à l'instar des identités culturelles du monde contemporain - se confronte en permanence à l'inachevé.» (p. 181) C'est dire que les thèses développées dans cet ouvrage débordent le cadre étroitement linguistique pour, face à une actualité questionnée par le paradigme de l'altérité et la crise des appartenances communautaires et/ou nationales, interroger les mutations identitaires et culturelles que langage et traduction à la fois reflètent et provoquent. En ce sens Le trafic des langues est essentiel à l'émergence d'une nouvelle pensée traductologique prenant en compte les dimensions éthiques et politiques de son objet, condition indispensable à l'exercice d'une critique pleinement de son temps. 
Notes

1. Malgré la réserve de l'auteur: «Nous avons de toute évidence affaire à des pratiques qui chevauchent les fontières normalement attribuées à la traduction, à l'écriture, et au commentaire, pratiques qui seront à rapprocher de la performance, qui se veut un événement toujours à recommencer. Il nous manque un vocabulaire conceptuel propre à rendre compte de ces expériences.» (p. 179) 